\title{
ISSN 1411 - 5247 \\ Penerapan Proses Integrasi Kegiatan Pemindahan Hasil Rebusan Sari Kedelai Ke Bak Penyaringan Pabrik Tahu Di Batam (Studi Kasus Pabrik Tahu Pak Joko Dan Pak Udin)
}

\author{
Benedikta Anna Haulian Siboro ${ }^{1}$, Vera Methalina Afma ${ }^{2}$,Mohamad Sulaiman ${ }^{3}$ \\ 1,2, Dosen Program Studi Teknik Industri, Mahasiswa Program Studi Teknik Industri ${ }^{3}$ \\ Fakultas Teknik, Universitas Riau Kepulauan Batam \\ Jl. Batu Aji baru, Batam, Kepulauan Riau \\ Email : b.anna79@gmail.com ${ }^{1}$, \\ Email : vera.afma@gmail.com² \\ Email : darkrepulser.sm@gmail.com ${ }^{3}$
}

\begin{abstract}
ABSTRAK
Pabrik tahu Pak Udin dan Pak Joko adalah pabrik pembuat tahu yang seluruh proses dilakukan secara manual, khususnya di bagian pemindahan sari kedelai dari bak rebus ke bak saring. Berat beban yang diangkat adalah $\pm 30 \mathrm{~kg}$ dengan suhu $85-90^{\circ} \mathrm{C}$ dan repetisi sebanyak 30 kali. Hal tersebut melebihi batas angkat yang di tetapkan oleh NIOSH yaitu 24.5

Penelitian ini bertujuan untuk melakukan perbaikan proses dengan menerapkan proses terintegrasi pada bak perebusan dan bakpenyaringan agar dapat mengeliminasi proses angkat dan meningkatkan efesiensi waktu dengan menggunakan metode Ovako Work Analysis System, Antropometri dengan postur kerja berdiri dan jam henti.

Hasil data OWAS meenunjukkan bahwa postur tubuh pengangkatan air rebus kedelai berbahaya bagi kesehatan dan keselamatan pekerja (nilai OWAS yang diperoleh 3,5). Selanjutnya desain dikembangkan dengan mengintegrasikan stasiun bak perebusan dan penyaringan menggunakan mesin pompa dan pipa penghubung sehingga nilai OWAS menjadi nilai 1 yang berarti tidak ada masalah pada postur akhir. Untuk dimensi antropometri yang digunakan adalah Tinggi bahu berdiri 136,4 cm untuk tinggi keran output, tinggi mata berdiri 148,8 untuk tinggi sakelar mesin, dan jangkauan tangan kedepan untuk jarak keran input. Waktu siklus yang awal dan setelah perancangan adalah 4,8 menit menjadi 3,2 menit.
\end{abstract}

Kata kunci: OWAS, Antropometri, jam henti 


\section{Pendahuluan}

Menurut Widyaningrum (2015), tahu memiliki protein nabati kualitas terbaik karena memiliki komposisi asam amino paling lengkap dan diyakini memiliki daya cerna yang tinggi (sebesar $85 \%$-98\%) sehingga tahu menjadi salah satu makanan kesukaan dari kebanyakan orang. Beberapa usaha tahu yang ada di kota Batam adalah Pabrik Tahu Pak Joko dan Pak Udin. Kedua Pabrik ini memproduksi jenis tahu yang berbeda. Pabrik Tahu Pak Udin memproduksi dua jenis produk tahu yaitu tahu goreng dan tahu mentah sedangkan Pabrik Tahu Pak Joko memproduksi tahu putih. Adapun proses pembuatan tahu meliputi: proses pencucian, penggilingan, perebusan, penyaringan, pengepresan, dan pemotongan serta finishing. Salah satu akibat dari stasiun kerja yang tidak ergonomis muncul dari sikap kerja yang tidak fisiologis seperti jongkok, membungkuk, duduk bersila dan sebagainya (Sundari, 2011). Selain itu pada kegiatan pemindahan hasil rebusan sari tahu dari bak rebus ke bak saring dilakukan dengan keadaan beban yang diangkat $\pm 30 \mathrm{~kg}$ dengan repetisi 30 kali sekali siklus rebus. Menurut ILO dalam (NIOSH, 1981) berat beban yang dianjurkan untuk pria dewasa usia 2025 adalah $24,5 \mathrm{~kg}$. Penelitian yang telah dilakukan oleh (Santoso, 2006) menjelaskan juga mengenai maximum acceptable weight of lift untuk pekerja Indonesia dengan repetisi 2 , 4, dan 8 kali/menit secara berturut adalah 13,77 $\mathrm{kg}, \quad 12,80$ dan 11,25 dalam $\mathrm{kg}$. Berdasarkan latarbelakang diatas maka penelitian ini bertujuan untuk mengeliminasi aktifitas angkat manual dan meningkatkan efisiensi waktu proses pengangkatan air rebusan ke bak penyaringan.

\section{Bahan dan Metode Penelitian}

\subsection{Landasan Teori}

a. Ovako Work Posture Analysis

\section{System (OWAS)}

Manusia merupakan bagian dari suatu sistem kerja mempunyai kelebihan dan keterbatasan dalam melaksanakan fungsinya dalam sistem kerja, sehingga analisa biomekanika sangat penting dilakukan untuk mengetahui cara kerja operator dan dampaknya bagi kesehatan dan keselamatan kerja. Ada beberapa metode biomekanika untuk analisis sikap kerja salah satu nya yaitu Ovako Work Posture Analysis System (OWAS). Menurut Karhu et al dalam (Triyono, 2006), OWAS bertujuan untuk analisis sikap kerja yang mendefinisikan pergerakan tubuh bagian punggung, lengan, kaki, dan berat beban yang diangkat. Klasifikasi postur dasar OWAS terdiri dari empat jenis, yaitu punggung, lengan, kaki, dan berat beban yang diangkat.

\section{b. Antropometri}

Pada antropometri, ukuran dimensi tubuh manusia menjadi pertimbangan dalam proses perancangan stasiun kerja (Wignjosoebroto, 2006).

Dalam stasiun kerja berdiri ada beberapa dimensi yang perlu diperhatikan sebagai panduan dalam pengukuran dan pengambilan data antropometri(Iridiastadi \& Yassierli, 2014), yaitu: tinggi badan tegak (TBT), tinggi mata berdiri (TMB), tinggi bahu berdiri (TBB), tinggi siku berdiri (TSB) dan jangkaun tangan kedepan (JTK).

Berikut merupakan tata cara dalam pengujian data menurut (Purbasari \& Benedikta, 2017)

1. Uji kecukupan data

$$
N^{\prime}=\left[\frac{k / s \sqrt{N \Sigma^{X^{2}-(\Sigma X)^{2}}}}{\Sigma X}\right]^{2}
$$

Dimana nilai $\mathrm{k} / \mathrm{s}=20$ (dengan tingkat keyakinan $95 \%$ dan derajat ketelitian $10 \%$ ) 
2. Uji normalitas

3. Uji keseragaman data, dengan menggunakan batas kontrol atas dan bawah

$\sigma=\left[\sqrt{\frac{\sum(X-X i)^{2}}{N-1}}\right]$

$\sigma=$ standar deviasi

$$
\begin{aligned}
& \mathrm{BKA}=\bar{x}+(3 \mathrm{x} \mathrm{SD}) \\
& \mathrm{BKB}=\bar{x}-(3 \mathrm{xD})
\end{aligned}
$$

\section{c. Studi Waktu}

Menurut (Wignjosoebroto, 2006), studi waktu menggunakan jam henti diaplikasikan untuk pekerjaan yang berlangsung singkat dan berulang-ulang dengan rumusan sebagai berikut:

1. Waktu normal

$\mathrm{Wn}=\mathrm{Ws} \times \mathrm{p}$

$\mathrm{P}=$ performance rating

2. Waktu Baku

Wn $x \frac{100 \%}{100 \%-\% \text { allowance }}$ (jam/unit)

\section{d. Pemilihan Pompa}

Menurut Sularso dalam (Wahyudi, 2013), pompa berfungsi untuk memberikan energi kepada fluida, dimana dalam hal ini fluida adalah zat cair, sehingga zat cair tersebut dapat dipindahkan dari satu tempat ketempat lain. Pemilihan pompa harus seefektif mungkin sehingga kebutuhan daya penggerak bisa diminimumkan (Karnowo \& Anis, 2008). Adapun beberapa hal yang harus diperhatikan dalam pemilihan pompa adalah.

a. Kapasitas

b. Head (tinggi tekan)

$H_{\text {pompa }}=\left(\Delta Z+\Delta \frac{p}{\rho g}+\Delta \frac{v^{2}}{2 g}\right)+H_{\text {losses }}$

Dimana :

$\Delta \mathrm{Z}=$ head elevasi $(\mathrm{m})$

$\Delta \frac{p}{\rho g}=0$ karena reservoir atas dan bawah tekanan airnya sama (Ubaedilah, 2016)
$\Delta \frac{v^{2}}{2 g}=$ head kecepatan sisi masuk dan keluar (m)

$H_{\text {losses }}=$ head kerugian (m)

$\mathrm{NPSHa}=h_{s v}=\frac{p_{a}}{\gamma}-\frac{p_{v}}{\gamma}+h_{s}-h_{l s}$

Syarat pemilihan pompa adalah NPSHa $>\mathrm{NPSHr}$

\subsection{Metodologi Penelitian}

Penelitian ini dilakukan di Pabrik Tahu Pak Udin dan Pak Joko di Batam, dengan stasiun kerja yang diamati adalah perebusan dan penyaringan. Subjek penelitian ini dilakukan pada operator yang melakukan kegiatan pemindahan hasil rebusan sari kedelai ke bak saring yang bertujuan untuk pergerakan tubuh bagian punggung, lengan, kaki, dan berat beban yang diangkat, sehingga dapat dianalisa dengan menggunakan OWAS. Langkah selanjutnya, dengan menghitung antropometri operator tersebut yang diharapkan desain yang dibangun sesuai dengan postur tubuh operator. Studi waktu dengan jam henti untuk mengetahui dan membandingkan waktu normal dan waktu baktu proses perebusan dan penyaringan untuk sistem yang lama dan sistem yang baru (sistem integrasi).

\section{Analisa Data dan Pembahasan \\ a. Perhitungan Nilai OWAS}

Pada hasil perhitungan dan analisa tabel klasifikasi OWAS nilai sebelum implementasi sistem integrasi adalah 3,5 dengan hasil analisa adalah sikap kerja berbahaya bagi sistem muskuloskeletal dan perlu perbaikan sesegera mungkin. Berikut ini adalah postur tubuh salah satu operator di stasiun kerja perebusan. Pada saat melakukan pemindahan air rebusan kedelai ke stasiun penyaringan air kedelai operator mengangkat secara 
manual. Berikut gambaran proses pengangkatan air rebusan kedelai.

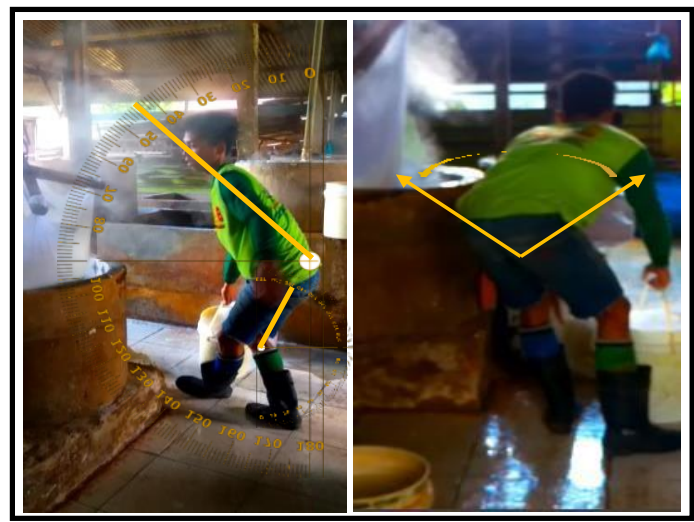

Gambar 1. Postur Tubuh saat pengangkatan air rebusan kedelai ke stasiun penyaringan air kedelai

\section{b. Perhitungan Antropometri}

Data dimensi tubuh pekerja ini diukur terhadap seluruh operator pada kedua pabrik ini dengan postur kerja berdiri. Berikut merupakan hasil perhitungan data dimensi tubuh menggunakan antropometri:

Tabel 1. Dimensi Tubuh Operator

\begin{tabular}{|l|c|c|c|c|c|}
\hline Area & $\begin{array}{c}\text { Rata } \\
\text {-rata }\end{array}$ & $\boldsymbol{\sigma}$ & P5 & P50 & P95 \\
\hline TBT & 164,6 & $\begin{array}{c}8,6 \\
5\end{array}$ & $\begin{array}{c}150,3 \\
7\end{array}$ & 165 & $\begin{array}{c}178, \\
8\end{array}$ \\
\hline $\begin{array}{l}\text { TM } \\
\text { B }\end{array}$ & 148,8 & 7,5 & $\begin{array}{c}136,4 \\
7\end{array}$ & 149 & $\begin{array}{c}161, \\
1\end{array}$ \\
\hline TBB & 136,4 & $\begin{array}{c}9,1 \\
7\end{array}$ & $\begin{array}{c}122,9 \\
6\end{array}$ & 136 & $\begin{array}{c}149, \\
8\end{array}$ \\
\hline JTK & 70,2 & $\begin{array}{c}3,5 \\
6\end{array}$ & $\begin{array}{c}64,34 \\
7\end{array}$ & 76,1 \\
\hline
\end{tabular}

\section{c. Waktu Siklus dan Waktu Baku}

Pada perhitungan waktu normal dan waktu baku diperlukan nilai $\mathrm{p}$ dan nilai allowance, untuk nilai $\mathrm{p}$ adalah 1,12 dan nilai allowance adalah 46, maka perhitungan waktu normal dan waktu baku adalah.

$$
\begin{aligned}
\mathrm{Wn} & =9,6 \times 1,12 \\
& =10,75 \text { detik } \\
\mathrm{Wb} & =19,9 \text { detik }
\end{aligned}
$$

\section{d. Perhitungan Pompa}

Berdasarkan hasil perhitungan pompa, nilai debit yang dibutuhkan 12000 liter/jam, kecepatan aliran 1,697 $\mathrm{m} / \mathrm{s}$, total head 1,88 meter serta perhitungan NPSHa adalah 10,73 meter. Sehingga berdasarkan kebutuhan debit tersebut maka pompa yang dipilih adalah pompa merk VENZ seri VS100/2 dengan kapasitas 50 - 350 liter/menit, kapasitas kebutuhan head 200 liter $/$ menit $=10,3$ meter $($ NPSHr $)$. Maka diketahui nilai NPSHr > NPSHa $=10,73>10,3$.

\section{e. Dimensi Alat Integrasi}

Untuk dimensi akan digunakan nilai hasil hitungan persentil. Berikut merupakan dimensi alat berdasarkan persentil.

Tabel 2. Dimensi rancangan

\begin{tabular}{|l|c|l|c|}
\hline \multicolumn{3}{|c|}{ Dimensi Rancangan Meja } \\
\hline \multicolumn{1}{|c|}{ Dimensi } & Persentil & \multicolumn{1}{|c|}{ Alasan } & Nilai (cm) \\
\hline $\begin{array}{l}\text { Tinggi Keran } \\
\text { output }\end{array}$ & TBB-50 & $\begin{array}{l}\text { Agar subjek dengan ukuran P95 dan P5 tidak } \\
\text { memiliki kesulitan dalam menggunakan keran }\end{array}$ & 136,4 \\
\hline $\begin{array}{l}\text { Tinggi Sakelar } \\
\text { Mesin }\end{array}$ & TMB-50 & $\begin{array}{l}\text { Agar subjek dengan ukuran P95 dan P5 tidak } \\
\text { memiliki kesulitan dalam menggunakan sakelar }\end{array}$ & 148,8 \\
\hline $\begin{array}{l}\text { Jarak keran } \\
\text { Input }\end{array}$ & JTK-50 & $\begin{array}{l}\text { Agar subjek dengan ukuran P95 dan P5 tidak } \\
\text { memiliki kesulitan dalam menggunakan keran }\end{array}$ & 70,2 \\
\hline $\begin{array}{l}\text { Pembatas tinggi } \\
\text { alat }\end{array}$ & TBT-5 & $\begin{array}{l}\text { Sebagai panduan agar alat tidak melebihi tinggi } \\
\text { badan tegak para pekerja }\end{array}$ & 150,37 \\
\hline
\end{tabular}

Berdasarkan dimensi tersebut berikut merupakan desain dari alat integrasi dalam bentuk gambar 2 dimensi.



Gambar 2. Desain Alat Integrasi

f. Evaluasi Sebelum dan Setelah Perancangan Sistem Integrasi 


\section{Evaluasi Desain}

Penelitian sebelumnya telah dilakukan di tempat yang sama dengan mengusulkan desain proses pengangkatan sari kedelai ke penyaringan(Siboro, Siagian, \& Purbasari, 2017). Berikut perbandingan desain penelitian sebelumnya dan penelitian ini:

\begin{tabular}{|c|c|}
\hline Usulan Penelitan Sebelumnya & Penelitianini \\
\hline & \\
\hline Pipa berdiameter $12 \mathrm{~cm}$ & Pipa berdiameter $5 \mathrm{~cm}$ \\
\hline $\begin{array}{l}\text { Keran berjumiah } 1 \text { buah dan } \\
\text { berdiameter } 9 \mathrm{~cm}\end{array}$ & $\begin{array}{l}\text { Keran berjumlah } 4 \text { buah dan } \\
\text { berdiameter } 5 \mathrm{~cm}\end{array}$ \\
\hline $\begin{array}{l}\text { Elbow berdiameter } 12 \mathrm{~cm} \text { jumlah } \\
\text { tidak disebutkan }\end{array}$ & $\begin{array}{l}\text { Elbow berdiameter } 5 \mathrm{~cm} \text { bejumiah } 4 \\
\text { buah }\end{array}$ \\
\hline $\begin{array}{l}\text { Pompa yang digunakan berjenis } \\
\text { Rotary } \\
\text { dengankapasitas } \\
\text { 1. S.Head } 9 \text { meter } \\
\text { 2. H.Max } 3 \text { Meter } \\
\text { 3. Kapasitas debit, diameterinput, } \\
\text { output tidak disebutkan }\end{array}$ & $\begin{array}{l}\text { Pompayang digumakan berjeris } \\
\text { Sentrifugal dengan Impeler kningan } \\
\text { untukketahanan suhutinggi dengan } \\
\text { spesifikas } \\
\text { 1. S.head } 7 \text { meter } \\
\text { 2. H.max } 13 \mathrm{Meter} \\
\text { 3. Max Debit } 350 \text { ittermerit } \\
\text { 4. Diameter input dan output } 5 \mathrm{~cm}\end{array}$ \\
\hline Total Head tidak diperhitungkan & Total Head 1,88 meter \\
\hline $\begin{array}{l}\text { Pemasanganpipa mashbelum } \\
\text { teratur dan menganggipergerakan } \\
\text { pekerja }\end{array}$ & $\begin{array}{l}\text { Pemasanganpipa tidakmengganggu } \\
\text { pergerakanpekerja }\end{array}$ \\
\hline
\end{tabular}

\section{Gambar 4 Perbandingan Desain}

\section{Evaluasi OWAS}

Pada keadaan saat proses pemindahan sari tahu dilakukan oleh mesin pompa, penilaian dengan OWAS diperoleh nilai 1 yang berarti tidak ada masalah pada sistem muskuloskeletal dan tidak perlu perbaikan. Hal ini menunjukan bahwa setelah pemasangan alat integrasi terdapat kemajuan dimana postur kerja angkat yang dilakukan pekerja telah dieliminasi dan digantikan oleh mesin pompa sebagai media pemindah sari tahu dari bak rebus ke bak penyaringan. Berikut ini kondisi postur tubuh operator:

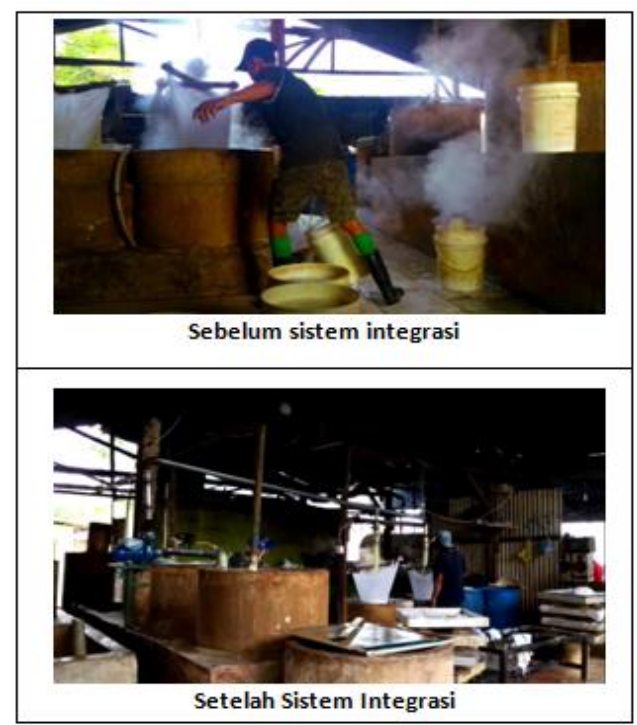

\section{Gambar 5. Perbandingan Postur Tubuh}

Pada gambar diatas dengan melihat kondisi setelah sistem integrasi, sudah tidak terlihat operator mengangkat air rebusan kedelai sebagaimana yang terlihat pada gambar sebelum adanya sistem integrasi.

\section{Evaluasi Waktu siklus}

Sebelum adanya sistem intergrasi, proses pengangkatan air rebus kedelai ke bak penyaringan membutuhkan 30 kali pengangkatan dalam satu bak perebusan. Setelah pemasangan sistem integrasi sudah tidak lagi proses pengangkatan sehingga waktu yang dihitung.

Tabel 3. Perbandingan Waktu Siklus

\begin{tabular}{|c|c|c|}
\hline \multicolumn{3}{|c|}{ Perbandingan Waktu } \\
\hline Jenis Waktu & Sebelum & Setelah \\
\hline Waktu Siklus & 4,8 Menit & 3,2 Menit \\
\hline Waktu Baku & 9,95 Menit & 4,2 Menit \\
\hline
\end{tabular}




\section{Kesimpulan dan Saran 4.1 Kesimpulan}

Berikut merupakan kesimpulan dari hasil analisa dan evaluasi yang telah dilakukan;

a. Penerapan proses terintegrasi telah mengeliminasi aktifitas angkat manual, dimana dinyatakan dari nilai OWAS awal 3,5 menjadi 1 .

b. Peningkatan efesiensi waktu telah tercapai setelah penerapan proses terintegrasi, dimana dinyatakan dari nilai waktu siklus dan waktu baku sebelum terhadap sesudah adalah, 4,8 menjadi 3,2 menit dan 9,95 menit menjadi 4,2 menit.

\subsection{Saran}

Saran yang dapat diberikan terkait hasil penelitian ini:

a. Pihak pekerja agar melakukan pembersihan alat di akhir produksi untuk menjaga keawetan.

b. Pihak pemilik pabrik tahu agar lebih memperhatikan aspek kebersihan pabrik agar kehigenisan dan kualitas tahu tetap terjaga

\section{Ucapan Terima Kasih}

Terima kasih kepada pihak terkait seperti Pabrik Tahu Pak Udin dan Pak Joko yang memberikan tempat untuk melakukan penelitian, Ristekdikti yang memberikan kesempatan dalam melakukan pengabdian masyarakat dan rekan-rekan lainnya yang membantu dalam penelitian ini.

\section{DAFTAR PUSTAKA}

Iridiastadi, H., \& Yassierli. 2014. Ergonomi Suatu Pengantar. (Nia, Ed.) (1st ed.). PT. Remaja Rosdakarya: Bandung

Karnowo, \& Anis, S. 2008. BUKU AJAR: Dasar Pompa. Semarang: Universitas Negeri Semarang.

NIOSH. 1981. Work Practice Guide for Manual Lifting. Ohio.
Purbasari, A., \& Benedikta, A. 2017. Modul Praktikum APK dan Ergonomi. Batam: Universitas Riau Kepulauan.

Santoso, D. 2006. Kapasitas Angkat Beban Untuk Pekerja Indonesia. Jurnal Teknik Industri, 8(2), 148155.

Siboro, B. A. H., Siagian, M. F., \& Purbasari, A. 2017. Usulan Desain Proses Pengangkatan Sari Kedelai ke Penyaringan (Studi Kasus Pabrik Tahu di Batam ). Prosiding SNTI Dan SATELIT, 119-124.

Sundari, K.N . 2011. Sikap Kerja yang Menimbulkan Keluhan Musculoskeletal dan Meningkatkan Beban Kerja pad Tukang Bentuk Keramik, Jurnal Ilmiah Teknik Industri Vol.10(1) ,42-47

Triyono.2006. Analisis sikap kerja pekerja manual material handling UD . Tetap Temangat dengan metode owas ( ovako working posture analysis system ). Universitas Sebelas Maret.

Ubaedilah.2016. Analisa Kebutuhan Jenis dan Spesifikasi Pompa untuk Suplai Air Bersih di GEdung Kantin Berlantai 3 PT.Astra Daihatsu Motor. Jurnal Teknik Mesin, 5(3), 119-127.

Wahyudi.2013. Analisis Perancangan Pompa Guna Pemenuhan Kebutuhan Air bersih PDAM Kota Probolinggo. Universitas Jember.

Widyaningrum, I.2015.Teknologi Pembuatan Tahu yang Ramah Lingkungan (Bebas Limbah), Jurnal Dedikasi Vol 12, 14-21

Wignjosoebroto, S.2006. Ergonomi Studi Gerak dan Waktu. (I. K. Gunarta, Ed.) (4th ed.). Prima Printing: Surabaya 